\title{
PENAFSIRAN HUKUM TENTANG KEBERSIHAN DAN PENCEMARAN \\ (KAJIAN TERHADAP PERATURAN GUBERNUR ACEH NOMOR 72 TAHUN 2018)
}

\author{
Roslaini Ramli ${ }^{1}$, Afini ${ }^{2}$ \\ Bagian Hukum dan Masyarakat Fakultas Hukum Universitas Syiah Kuala \\ Banda Aceh, Indonesia \\ E-mail: rosramli@unsyiah.ac.id
}

\begin{abstract}
ABSTRAK
Berdasarkan Peraturan Gubernur Aceh Nomor 72 Tahun 2018 tentang Kedudukan, Susunan Organisasi, Tugas dan Fungsi dari Unit Pelaksakan Teknis Daerah ((UPTD) Pelabuhan Perikanan Samudera Kutaraja Lampulo pasal 5 huruf (m) menyatakan bahwa UPTD Pelabuhan Perikanan Samudera Kutaraja Lampulo memiliki tugas sebagai pengendalian lingkungan yang meliputi, kebersihan, pencemaran, ketertiban dan keamanan. Penelitian ini ingin mengetahui makna kebersihan dan pencemaran dengan menggunakan teori penafsiran hukum dari Ronald Dworkin. Dengan menggunakan jenis metode penelitian limited style atau gaya terbatas hanya pada teks atau dokumen dari suatu peraturan perundang-undangan. Kebersihan dan pencemaran berdasarkan dari tujuan UPTD adalah menjaga kawasan pelabuhan dari sampah yang menumpuk, terhindar dari bau yang tidak sedap.
\end{abstract}

Kata kunci: Interprestasi, Kebersihan, Pencemaran, UPTD, Pelabuhan. 


\begin{abstract}
Based on Governor Aceh Regulation Number 72 of 2018 concerning the Position, Organizational Structure, Duties and Functions of the UPTD of the Samudera Kutaraja Lampulo Fishing Port, article 5 letter $(m)$ states that the UPTD of the Kutaraja Lampulo Samudera Fishery Port has a duty as environmental control which includes, cleanliness, pollution, and order. and security. This study wanted to find out the meaning of cleanliness and pollution by using Ronald Dworkin's theory of legal interpretation. By using this type of research method limited style or style limited only to text or documents of a statutory regulation. Cleanliness and pollution based on the purpose of the UPTD is to protect the port area from accumulated garbage, avoiding unpleasant odors.
\end{abstract}

Keywords: Interpretation, Cleanliness, Pollution, Grammatical, Port. 


\section{PENDAHULUAN}

Berdasarkan Peraturan Gubernur Aceh No 72 Tahun 2018 tentang Kedudukan, Susunan Organisasi, Tugas, Fungsi dan Tata Kerja Unit Pelaksana Teknis Daerah Pelabuhan Perikanan Samudera Kutaraja Pada Dinas Kelautan Dan Perikanan Aceh pasal 5 huruf (m) menyatakan bahwa pelaksanaan pengendalian lingkungan meliputi kebersihan, keamanan, ketertiban dan pencemaran merupakan salah satu tugas dari UPTD PPS Kutaraja Lampulo. Hasil wawancara Kepala Dinas Kelautan dan Perikanan (DKP Aceh) Pengelolaan Pelabuhan Perikanan belum memberikan kenyaman bagi masyarakat yang ingin membeli ikan karena kotor, sampah yang menumpuk, aroma yang tidak sedap tercium dari lokasi penjualan ikan (Aceh Tribunnews,2019). Hasil penelitian awal ditemukan sejumlah masalah khususnya tentang kebersihan dan pencemaran. (Afini,2020:3).

Kebersihan dan pencemaran sering terjadi karena kebiasaan nelayan, pembeli dan penjual yang membuang sampah sembarangan. Menurut beberapa penjual yang ada di Pelabuhan Perikanan Samudera Kutaraja Lampulo ada petugas yang membersihkan kawasan pelabuhan tetapi walau sudah dibersihkan kebersihan yang ada diarea pelabuhan masih kurang bersih karena sampah terlihat bertebaran di beberapa area kawasan pelabuhan. Sedangkan untuk masalah pencemaran di kawasan Pelabuhan Perikanan Samudera Lampulo beberapa orang nelayan terlihat membuang ikan yang sudah mati ke dalam laut atau kolam pelabuhan, sehingga udara yang tercium ketika memasuki Pelabuhan Perikanan Samudera Kutaraja Lampulo bau yang tidak sedap, selain itu darah-darah ikan yang ada di dalam tong-tong penyimpanan ikan juga kadang-kadang dibuang langsung ke dalam kolam pelabuhan. Berdasarkan uraian permasalahan diatas penelitian ini ingin mengetahui apakah makna dari pengendalian lingkungan khususnya pencemaran dan kebersihan berdasarkan Peraturan Gubernur Nomor 72 Tahun 2018. (Afini, 2020:3).

Penelitian ini menggunakan konsep teori Ronald Dworkin khususnya tentang interprestasi hukum. Dworkin mengatakan bahwa hukum merupakan dimensi interpretatif. Interprestasi merujuk pada suatu proses mengembangkan suatu metode penafsiran atau teori yang paling baik menjelaskan apa hukumnya yang sebenarnya dalam situasi tertentu (what is the law actually in a particular situation).(Diah Imaningrum Susanti, 2015:5152) Interprestasi konstruktif yang mendasari teori hukumnya. (Diah Imaningrum Susatnti, 2015: 51-52). Dworkin mengatakan seseorang harus membebankan tujuan dan koherensi pada objek interprestasi untuk membuat contoh yang terbaik. Tujuan dari hukum mendesakkan agar kekuatan tidak digunakan, dipangkas kecuali atas izin atau dibutuhkan oleh hak-hak dan tanggung jawab individual yang berasal dari 
keputusan-keputusan politik di masa lalu tentang kapankah kolektif itu dijustifikasi. (Diah Imaningrum Susanti 2015:56-58).

Ada beberapa kajian yang meneliti tentang Pengelolaan Pelabuhan Perikanan Samudera Lampulo sebagai bahan rujukan bagi penulis dalam penelitian ini. ada beberapa persamaan dan perbedaan peneliti dengan bahan-bahan rujukan, adapun persamaan penulis dengan Afini tentang objek penelitian dan teori yang digunakan adalah Ronald Dworkin, sedangkan perbedaan penulis dengan Afini adalah Pengelolaan Pelabuhan Perikanan Samudera Kutaraja Lampulo pada Tahun 2020, Afini melihat apakah pelaksanaan pengendalian lingkungan meliputi: kebersihan, keamanan, ketertiban dan pencemaran di Pelabuhan Perikanan Samudera Kutaraja Lampulo memenuhi unsur-unsur keadilan berdasarkan teori Ronald Dworkin dan melihat bagaimanakah pelaksanaan pengendalian lingkungan yang meliputi kebersihan, keamanan, ketertiban dan pencemaran dalam law in the books and law in action. Selain itu perbedaannya adalah dalam menggunakan metode Afini menggunakan jenis penelitian Board Style, sedangkan penulis menggunakan jenis penelitian Limited Style atau gaya terbatas.

\section{METODE PENELITIAN}

Fokus penelitian ini adalah untuk menafsirkan kata kebersihan dan pencemaran di dalam Peraturan Gubernur No 72 Tahun 2018. Penelitian ini menggunakan jenis Limited Style atau gaya terbatas, penelitian ini hanya berkaitan dengan teks-teks peraturan perundangan-undangan atau biasa disebut sebagai penelitian studi doktrinal (Ronald Dworkin, 1973). Adapun teknik yang digunakan hanya membandingkan proposisi-proposisi dari teks dan teori. Bahan-bahan yang digunakan kamus,enksiklopedia, buku-buku yang berkaitan dengan penelitian ini.

\section{HASIL PENELITIAN DAN PEMBAHASAN}

Objek penelitian ini tentang Peraturan Gubernur Aceh No 72 Tahun 2018 Tentang Kedudukan, Susunan Organisasi, Tugas, Fungsi UPTD PPS Kutaraja Lampulo pasal (5) ayat 2 huruf (m) yaitu melaksankan tugas dalam mengendalikan kebersihan, pencemaran, ketertiban dan keamanan.

Berdasarkan hasil penelitian di Pelabuhan Perikanan Samudera Kutaraja Lampulo, menyatakan puas dengan kebersihan yang ada di Pelabuhan Perikanan Samudera Lampulo dan beberapa menjawab tidak puas. Peneliti kemudian menanyakan lagi alasan kenapa mereka puas dan tidak puas. Bebarapa subjek yang bernama Marco menjawab karena ini wilayah pelabuhan perikanan maka siapapun akan mengerti dan merasa puas dengan kondisi kebersihan yang ada di Pelabuhan Perikanan Samudera Lampulo. Sedangkan jawaban dari 
subjek yang bernama Iwan mengatakan bahwa beliau tidak puas akan kondisi yang ada di Pelabuhan Perikanan Lampulo. (Afini,2020:24).

Pengertian pencemaran berdasarkan gramatikal adalah proses, cara perbuatan yang mencemari lingkungan, seperti udara, air, tanah dan laut. Pencemaran yang terjadi di pelabuhan Perikanan di Indonesia mengalami banyak permasalahan terutama terkait sanitasi dan higienitas yang masih buruk. Lubis (2012) mengatakan secara umum kondisi pelabuhan perikanan di Indonesia selama ini masih dipandang kurang baik karena kotoran dan kekumuhan masih terlihat di area sekitar pelabuhan (Aris Wahyudi dkk, 2017:140).

Pelabuhan Perikanan Samudera Lampulo merupakan pelabuhan tipe A atau Samudera yang tujuan kegiatannya untuk ekspor ikan dan hasil pemasaran ikannya sekurangkurangnya 50 Ton perhari. Berdasarkan data Perkembangan Produksi Ikan yang didaratkan di PPS Kutaraja Lampulo pada tahun 2014-2019 Produksi ikan yang jumlah volumenya menunjukan peningakatan produksi setiap tahunnya dimana pada tahun 2019 sebesar 20.033,24 ton meningakat hingga mencapai 2.12,6 ton atau $12,2 \%$ dari produksi tahun sebelumnya (Afini,2020:25).

Aktivitas pendaratan, pengolahan dan pemasaran ikan di Pelabuhan Perikanan Samudera Lampulo dalam pengelolaanya belum memperhatikan kondisi lingkungan. Sehingga Pelabuhan Perikanan Samudera Lampulo terlihat kotor, kumuh dan bau, yang terindikasi dari limbah, seperti oli yang dibuang oleh para nelayan atau ABK (anak buah kapal) ke kolam pelabuhan, potongan-potongan ikan yang sudah busuk, air bekas pencucian ikan, darah ikan, ceceran minyak pada saat pengisian bahan bakar kapal. Pane (2008) mengatakan keberadaan potongan-potongan ikan, ikan yang busuk, genangan cairan dan lender baik di dermaga pendaratan atau dermaga bongkar muat ikan dan di tempat pelelangan ikan menjadi pertanda sanitasi dan higienitas di lingkungan pelabuhan perikanan. (Afini, 2020:25).

Berdasarkan hasil penelitian melalui pengamatan dan wawancara dengan koordinator Pelabuhan Perikanan Samudera Lampulo mengatakan bahwa di dalam mengatasi pencemaran yang ada di Pelabuhan Perikanan Samudera Lampulo, UPTD memiliki fasilitas pengolahan air limbah yaitu penyulingan air limbah sebelum masuk kelautan, tetapi beliau mengatakan bahwa perilaku masyarakat yang ada di Pelabuhan Perikanan Samudera Lampulo masih sangat tidak bisa diatasi, karena banyak faktor yang mempengaruhinya salah satunya menurut beliau adalah kurangnya pendidikan, kebiasaan dan kurangnya kepedulian terhadap lingkungan (Afini,2020:26).

Berdasarkan hasil wawancara dengan beberapa subjek seperti nelayan, ABK dan pengunjung yang ada di Pelabuhan Perikanan Samudera Kutaraja Lampulo mereka mengatakan bahwa kondisi kawasan pelabuhan 
perikanan nyaman dan bersih tetapi ada beberapa subjek yang lain mengatakan bahwa kawasan pelabuhan perikanan kurang nyaman dan tidak bersih. Jika mengacu pada Peraturan Gubernur Nomor 72 Tahun 2018 pasal (5) ayat 2 huruf (m) tugas dari UPTD PPS Kutaraja Lampulo melaksanakan kebersihan, pencemaran, ketertiban dan keamanan. UPTD membuat himbauan seperti dilarang membuang sampah sembarang, dilarang menjual makan dan minuman di sekitar kawasan pelabuhan perikanan tetapi pada kenyataannya masih banyak masyarakat yang tidak mendengar dan tidak peduli terhadap terhadap peringatan dan himbauan yang di buat oleh UPTD PPS Kutaraja Lampulo (Afini,2020:27-28).

Ada beberapa jenis interprestasi hukum sebagaimana ditulis dalam Black's Law Dictionary mengidentifikasi jenis-jenis penafsiran, namun ilmu hukum membagi sistem-sistem interprestasi yang berlaku untuk berbagai jenis teks hukum, seperti sistem interprestasi yang berlaku untuk konstitusi, interprestasi yang berlaku untuk UndangUndang, kontrak, dan wasiat. Dalam ilmu hukum ada 9 jenis penafsiran hukum, yaitu: (1) penafsiran otentik, penafsiran yang dilakukan dengan dengan bertanya pada perancang Undang-Undang atau badan pembuat UndangUndang tentang apa makna yang dimaksudkannya; (2) Penafsiran kebiasaan adalah penafsiran yang didasarkan pada pengaturan-pengaturan sebelumnya atas objek yang sama; (3) Penafsiran Ekstensif adalah penafsiran bebas yang dilakukan terhadap suatu peraturan perundang-undangan pada suatu kasus yang tidak dapat dilingkupi oleh kata-kata harfiah dalam ketentuan tersebut; (4) penafsiran gramtikal penafsiran yang didasarkan sematamata pada kata-kata itu sendiri;(5) penafsiran liberal adalah penafsiran apa yang diyakini oleh pembaca, bahwa apa yang masuk akal itulah sebenarnya yang dimaksudkan walau peracangnya sendiri pun tidak memikirkan hal itu; (6) penafsiran terbatas adalah penafsiran yang terikat pada prinsip-prinsip yang terdapat di luar teks; (7) penafsiran logis adalah penafsiran yang memisahkan diri dari kata-kata harafiah berdasarkan bukti lain yang lebih menyakinkan dari maksud penulis; penafsiran ketat adalah penafsiran menurut apa yang diyakini pembaca sebagai yang mestinya dipikirkan oleh penulisnya pada saat menuliskanya; (9) penafsiran longgar adalah penafsiran yang berdasarkan itikad baik, tanpa merujuk pada prinsip-prinsip tertentu manapun (Diah Imaningrum Susanti, 2015:74-77).

Sedangkan teori Intensionalisme yang mengatakan bahwa makna teks adalah makna yang dimaksudkan oleh si 'pembicara'. intensionalisme berpusat pada maksud pembuatnya pada saat ditulisnya teks hukum. Aspek yang seringkali ditinjau dalam teori interprestasi adalah sejauh mana mendasarkan 
gagasan tentang maksud yang dianggapkan (counterfactual/intention/hipotesis). Intensional melihat pada penalaran counterfactual yaitu penalaran tentang maksud yang semestinya dimiliki oleh penulis dalam kondisi yang lebih optimal daripada kondisi yang sebenarnya diperoleh (Diah Imaningrum Susanti,2015:83104).

Sedangkan interprestasi value maximizing adalah interprestasi yang berkorespondensi dengan nilai-nilai moral. Teori inteprestasi ini mengklaim bahwa interprestasi adalah proses dipromosikannya seperangkat nilai yang sesuai, pantas, patut pada teks atau masalah yang dihadapi. Dalam hukum, nilai-nilai yang memadai adalah nilai-nilai moral dan nilai-nilai hukum. Penganut teori ini adalah Ronald Dworkin dengan interprestasi konstruktifnya yaitu penafsir membebankan nilai atau tujuan pada praktik atau teks agar membuatnya menjadi contoh yang baik dalam genre yang dimilikinya. Dworkin mengatakan ketika menafsir, penafsir memiliki latar pengalaman, yaitu fenomenologisnya. Latar pengalaman ini menyediakan penjelasan tentang 'sikap interpestasi' atau interpretatif attitude dari para penafsir. Dworkin menyarankan agar penafsir berusaha untuk melihat praktik dan merestrukturkannya berdasarkan basis itu. Penafsir bertanggung jawab untuk untuk mempromosikan nilai itu dengan menempelkan apa yang dianggap sebagai tujuan sepatutnya yaitu nilai yang ada dan seharusnya ada (Diah Imaningrum Susanti, 2015:125).

\section{Penafsiran konstruktif Dworkin adalah} usaha untuk memberi makna pada suatu objek, teks atau praktik, jadi Dworkin tidak membedakan penafsir itu hakim atau bukan hakim, sejauh seseorang bisa memberikan makna. Ketika suatu objek adalah suatu aktivitas atau praktik, penafsir berusaha untuk memberlakukan makna praktisnya yang berarti membongkar nilai-nilai konkret dan abstrak yang mengatur interaksi dan menjalaskan wacanannya, sehingga ada alasan bagi partisipasi untuk bertindak dalam cara-cara tertentu (Diah Imaningrum Susanti, 2015:126).

Sikap interpretative dicirikan oleh dua asumsi. Pertama, praktik harus melayani suatu kepentingan, prinsip atau tujuan yang dapat dinyatakan tanpa menguraikan aturan dari praktik itu. Kedua, syarat dari praktik peka pada hal yang penting yaitu syarat-syarat yang dipahami untuk melayani hal yang penting dan bertanggung jawwab untuk memodifikasi pemahaman untuk memperdalam dan mengubah. Dworkin mengatakan ada dua interprestasi konstruktif, yaitu: a. Suatu interprestasi harus sesuai/cocok/mencocoki dengan sejarah dan praktik; b. Suatu interprestasi harus dibenarkan oleh nilai-nilai yang sesuai dengan wilayah untuk mana yang praktik atau teks, atau memahami hubungan antara fit dan justification dalam berbagai cara. Misalnya satu pendekatan mengatakan bahwa 
penafsir harus melaksanakan yang fit dulu, setelah itu jika ada lebih dari satu interprestasi yang secara moral terbaik (morally best) adalah yang benar (Diah Imaningrum Susanti, 2015:127).

Pendekatan yang kedua menyiratkan bahwa sejarah dan prinsip-prinsp moral yang mendasarinya seharusnya dibawa ke dalam keseimbangan reflektif untuk menjawab pertanyaan-pertanyaan interprestasi yang dihadapi saat ini. Nilai-nilai moral yang paling penting untuk dimensi pembenaran dapat dipahami sebagai nilai-nilai moral yang tersirat dalam sejarah praktik atau semua hal yang dianggap sebagai nilai (Diah Imaningrum Susanti, 2015:128).

Selanjutnya menurut Dworkin bentuk interprestasi bergantung pada kemampuan untuk menempatkan suatu nilai atau tujuan yang khas/ pada objek ketika objek itu adalah suatu praktik sosial, sebanyak kita menempatkan nilai atau tujuan yang khas suatu karya seni. Dworkin juga mengatakan untuk memahami suatu praktik sosial, seorang ilmuwan sosial harus menjadi partisipan, tetapi sebagian orang perlu melihat apa maksud di balik intensi dari partisipan praktik itu dan menafsirkan secara konstruktif. Dworkin mengidentifikasi tiga tahap dalam interprestasi suatu praktik yang melibatkan suatu elemen preskriptif dan deskriptif (Diah Imaningrum Susanti, 2015:129).
Pertama harus ada tahap prainterprestasi (pra-interpretatif stage) di mana aturan dan standar diambil untuk menyediakan suatu muatan tentatif dari suatu praktik muatan tentatif dari suatu praktik yang diidentifikasi.

Selanjutnya ada tahap di mana penafsir menetapkan/menyepakati suatu pembenaran/justifikasi umum untuk elemenelemen utama dari praktik yang diidentifikasi tersebut, yang mensyaratkan suatu elemen yang “cocok”dengan detail-detail praktik.

Selanjutnya suatu tahap pascainterprestasi di mana penafsir menyesuaikan sensenya tentang apa yang sungguh-sungguh dibutuhkan praktik dalam memberikan pembenaran yang baik pada tahap interpretative itu. Pendekatan Dworkin bisa dibandingkan dengan model intensionalis dalam interprestasi. Untuk mendapatkan makna suatu tindakan, praktik atau teks, sebelumnya kita harus berusaha memastikan apa yang ada dalam benak si creator ketika membuatnya, yaitu apa yang dimaksud sang creator untuk diungkpakan. Untuk mengambil simpulan makna dari suatu teks hukum adalah dari tindakan manusia yang terlibat dalam dalam penciptaanya atau cerminan dari penulisnya (Diah Imaningrum Susanti, 2015:130). 


\section{SIMPULAN}

Berdasarkan Peraturan Gubernur Aceh Nomor 72 Tahun 2018 Tentang Susunan Organisasi, Tugas, Fungsi dari UPTD PPS Kutaraja Lampulo pasal 5 huruf (m) Kota Banda Aceh bersih sehingga UPTD menyatakan bahwa UPTD PPS Kutaraja bekerja sama dengan pihak Dinas Lingkungan Lampulo memiliki tugas sebagai pengendalian dan Kebersihan Aceh, dan mempekerjakan lingkungan yang meliputi: kebersihan, beberapa orang untuk membersihkan kawasan keamanan, ketertiban dan pencemaran. Hasil area pelabuhan. penelitian menujukkan bahwa secara tekstual makna kebersihan dari pembuat undang-undang adalah untuk merawat dan menjaga kebersihan di area pelabuhan atas dasar dari cita-cita dari program pemerintah yang ingin menjadikan

\section{DAFTAR PUSTAKA}

Afini, 2020, Pengelolaan Pelabuhan Perikanan Samudera Kutaraja Lampulo Ditinjau Dari Perspektif Keadilan Ronald Dworkin, Unpublished ETD Unsyiah, Universitas Syiah Kuala, Banda Aceh.

Diah Imaningrum Susanti, 2015, Penafsiran Hukum Yang Kompherensif Berbasis Lingkar Hermenutika, , Malang, iphils.

Ronald Dworkin, 1986, Law Empire, Cambridge, Massachusetts, The Press Belknap of Harvad University Press.

Ronald Dworkin, 2013, Justice For Hedgehogs, Cambridge, Masscahusetts, The Press Belknap of Harvad University Press. 